\title{
The Association between Allostatic Load and Mortality among Chinese Older Adults: The Chinese Longitudinal Health and Longevity Study
}

\section{Tianhang Zhang}

Imperial College London

\section{Lijing Yan}

Duke Kunshan University

\section{Huashuai Chen}

Duke University

Haiyu Jin

Duke Kunshan University

Chenkai Wu ( $\nabla$ chenkai.wu@dukekunshan.edu.cn )

Duke Kunshan University https://orcid.org/0000-0002-2256-0653

Research article

Keywords: Allostatic load, Mortality, China, Older adults

Posted Date: June 12th, 2020

DOl: https://doi.org/10.21203/rs.3.rs-31124/v1

License: (c) (1) This work is licensed under a Creative Commons Attribution 4.0 International License. Read Full License 


\section{Abstract \\ Background}

Allostatic load, as multiple biomarker measures of 'wear and tear' on physiological systems, has shown some promise that high burden of $\mathrm{AL}$ is associated with increased risk of adverse outcomes, but little attention has been paid to China with largest aging population in the world. This study is to examine the association between allostatic load (AL) and all-cause mortality among Chinese adults aged at least 60 years.

\section{Methods}

Data were from 2,439 participants in the Chinese Longitudinal Healthy Longevity Survey. The final analytic sample consisted of 1,519 participants. Cox models were used to examine the association between $\mathrm{AL}$ and mortality among men and women, separately. Analysis were also adjusted for potential confounders including age, ethnicity, education, and marital status, smoking and exercise.

\section{Results}

In the fully adjusted model, males with a medium AL burden (score: 2-4) and high AL burden (score: 5-

9) had a $34 \%$ and $128 \%$ higher hazard of death, respectively, than those with a low AL burden (score: $0-$ 1). We did not find significant difference between females with different levels of AL burden.

\section{Discussion}

Higher AL burden was associated with increased all-cause mortality among Chinese men aged at least 60 years. However, we did not find strong evidence about Allostatic load was associated with specific causes of death over the same follow-up period among women. In conclusion Intervention programs targeting modifiable components of the AL burden may help prolong lifespan for older adults, especially men, in China.

\section{Background}

Allostatic load ( $\mathrm{AL}$ ) is conceptualized as the cumulative wear and tear on multiple physiological systems resulting from repeated adaptation to stressors [17, 23, 24]. In the absence of a gold standard, many operational definitions of AL have been proposed. The most commonly used construct of AL was developed by Seeman and colleagues who have used two categories of biomarkers for quantifying AL $[15,24]$. The first category (called primary mediators) includes biomarkers the body releases in response to stress, such as cortisol and dehydroepiandrosterone sulphate (DHEA-S); the second category 
comprises comprises secondary outcomes that result from the effects of primary mediators. Example biomarkers are blood pressure (BP), cholesterol, and waist-hip ratio [24].

Previous studies have shown that a high burden of $A L$ is associated with increased risk of adverse outcomes including cardiovascular disease, functional decline, and mortality among older adults $[1,13$, $14,17,18,20,25]$. However, little attention has been paid to less developed regions, including China - the most populous country with the largest aging population in the world. In 2019, there were 249 million adults aged 60 years or above in China, accounting for $17.3 \%$ of its total population, and this number is projected to almost double in 2050, reaching 487 million [4, 5].

In this study, we used a large cohort study to examine the association between AL and all-causes mortality among Chinese men and women aged at least 60 years. We hypothesized that a higher burden of AL would be associated with increased risk of all-cause mortality among both older men and women in China.

\section{Methods}

\section{Data and Study Participants}

We used data from the Chinese Longitudinal Healthy Longevity Survey (CLHLS), an ongoing prospective, longitudinal study with the largest sample of the oldest old in China. Half of the counties and cities in 22 of the 31 provinces in China (covering $85 \%$ of the population) were randomly selected through a multistage cluster sampling approach. A wide range of socio-demographic, lifestyle, and health measures were collected in the CLHLS. The baseline survey was conducted in 1998 and participants who were alive were re-interviewed in each follow-up survey $(2000,2002,2005,2008-2009,2011-2012,2014$, and 2017-2018). In 2011-2012, an ancillary study, in which a blood test was added, was conducted in eight longevity areas: Laizhou City in Shandong Province, Xiayi County in Henan Province, Zhongxiang City in Hubei Province, Mayang County in Hunan Province, Yongfu County in Guangxi Autonomous Area, Sanshui District in Guangdong Province, Chengmai County in Hainan Province, and Rudong County in Jiangsu Province. The Research Ethics Committees of Peking University and Duke University granted approval for the Protection of Human Subjects for the CLHLS. All study participants gave informed consent. A more detailed description of the recruitment strategy and study design of the CLHLS has been published elsewhere [11, 31, 32].

A total of 2,439 persons contributed blood sample in the ancillary study (2011-2012). Participants were excluded from the analytic sample if they had (i) incomplete data on any biomarkers for constructing AL ( $n=251$ ), (ii) no follow-up data (time to death or censorship was undetermined; $n=552$ ), (iii) had extreme values on the biomarkers ( $n=109)$, or (iv) were less than 60 years old $(n=16)$. The final analytic sample consisted of 1,519 participants. We did not observe appreciable differences in age, ethnicity, marital status, smoking, or chronic conditions between the analytic sample and those excluded $(n=920$; Table 
S1). Compared to the analytic sample, excluded persons had higher education level and higher prevalence of exercise.

\section{Calculation of AL Score}

Based on previous research $[2,9,14,23]$ and availability of data in the CLHLS, we selected nine biomarkers to construct $\mathrm{AL}$ : heart rate, systolic BP (SBP), and diastolic BP (DBP), body mass index (BMI), total cholesterol, high density lipoprotein (HDL) cholesterol, glucose, triglyceride, and C-reactive protein (CRP). BMI, heart rate, SBP, and DBP were collected from physical examinations. BMI was calculated as body weight (kilograms) divided by height (meters) squared. SBP and DBP were measured by a mercury sphygmomanometer with an appropriately sized cuff, taken in the seated position after 5 minutes of quiet rest under the supervision of trained research assistants. We used the average of two measurements for further analyses. Blood samples were used for assays of the level of the total cholesterol, HDL cholesterol, glucose, triglyceride, and CRP.

To be in line with previous studies $[6,8,24,25]$, we used the highest quartile for heart rate, SBP, DBP, glucose, and CRP and the lowest quartile for HDL cholesterol to define high-risk group (coded 1). Because $\mathrm{BMI}$, total cholesterol, and triglyceride were inversely associated with mortality among older adults, especially the oldest old $[19,29,30]$, we used the lowest quartile to define high-risk group for these three biomarkers. For participants who self-reported having been diagnosed with hypertension and heart disease, we classified their SBP, DBP, and glucose into the high-risk category. Similarly, we classified participants' glucose into the high-risk group if they self-reported having been diagnosed with diabetes. The cut-points of all nine AL components by men and women were presented in Table 1. We constructed the AL score based on the count of biomarkers falling in the high-risk group, ranging from 0 (lowest) to 9 (highest). We then classified the AL score into three categories based on sample distribution: $0-1$ (low burden), 2-4 (medium burden), and 5-9 (high burden).

\section{Mortality}

The outcome was all-cause mortality. Vital status and date of death (for persons who died by the end of the study) was ascertained by the close family member or village doctor of the deceased participant during the follow-up survey in 2014 and 2017-2018. We calculated the survival time from the date of the baseline interview to the date of last interview (censored) or the death date.

\section{Covariates}

Demographic and lifestyle characteristics were collected by interview, including age, sex, ethnicity, education, and marital status, smoking status, and physical exercise. We divided ethnicity into Han and others (minority groups). Years of education were dichotomized as any (one year or more) and no education. Marital status was dichotomized as married and others (widowed, not married, and divorced). Cigarette smoking was categorized as current, past, and never smoker. Information of exercise was collected using the question "Do you do exercise at present?" and dichotomized into yes or no. Chronic conditions were measured based on self-reported physician's diagnosis, including hypertension, diabetes, Loading [MathJax]/jax/output/CommonHTML/jax.js 
heart disease, stroke, pulmonary disease (including bronchitis, emphysema, pneumonia and asthma), arthritis, and cancer.

\section{Statistical Analyses}

All analyses were conducted separately for males and females. We first presented the relative frequency of the AL score using histograms and calculated mean AL score. Then, we described the baseline characteristics of study sample by AL burden (low, medium, and high) using means and SDs for continuous variables and counts and percentages for categorical variables. Characteristics were compared across the three AL categories using analyses of variance for continuous variables and chisquare tests for categorical variables.

We calculated the death rates across three AL categories (low, medium, and high burden). We used the Cox proportional hazards model to determine the unadjusted and adjusted associations between the AL and all-cause mortality. Age, sex, education, and marital status were included in the demographically adjusted models; smoking status and physical exercise were added in the fully adjusted models. Because only about $6 \%$ of females were current or previous smokers, smoking status was modelled as a binary variable (never vs. current or previous) for females. We modelled AL both continuously and in categories. All tests were two-sided with a significance level of P-value less than 0.05 . We conducted all analyses using STATA version 16.0 (Stata Corp, College Station, TX).

\section{Results}

\section{Distribution of Allostatic Load Categories}

The distribution of the AL score (range: $0-9)$ is right-skewed for both males and females; only 13 (1.8\%) males and 10 (1.2\%) females had a score of 6-9, respectively (Fig. 1). The mean AL score was 2.56 (SD $=1.47$ ) for males and 2.28 (SD = 1.34) for females. For males, $25.5 \%, 65.3 \%$, and $10.3 \%$ had an AL score of $0-1,2-4$, and $5-9$, respectively. For females, $28.5 \%, 65.9 \%$, and $5.6 \%$ had an AL score of $0-1$ (low burden), 2-4 (medium burden), and 5-9 (high burden), respectively.

\section{Demographic Characteristics}

A total of $709(46.7 \%)$ males were included. The average age for males with an AL score of $0-1$ (low burden), 2-4 (medium burden), 5-9 (high burden) was 77.6, 81.0, and 84.1 years, respectively ( $P=$ 0.042). In addition, we observed significant differences in the prevalence hypertension and diabetes by different AL burden among males.

The study sample included 810 (53.3\%) females. The average age for females with an AL score of 0-1 (low burden), 2-4 (medium burden), 5-9 (high burden) was 87.0, 91.3, and 93.6 years, respectively $(\mathrm{P}<$ 0.05 ; Table 2). Females with a lower AL were more likely to be married and have any education than woman with hiaher AL score: thev also had a lower prevalence of hypertension, diabetes, and heart Loading [MathJax]/jax/output/CommonHTML/jax.js 
disease. We did not observe significant difference in ethnicity, smoking, physical exercise, stroke, pulmonary disease, arthritis, and cancer across AL burden (low, medium, and high) among females.

\section{Association between Allostatic Load and Mortality among Males}

A total of 310 males died; the overall death rate was 105.7 per 1,000 person-years. Males with an $A L$ score of 0-1 (low), 2-4 (medium), and 5-9 (high) had a death rate of 66.1, 110.4.6, and 201.3 per 1,000 person-years, respectively (Table 3 ).

In the unadjusted Cox model, per unit higher AL score was significantly associated with a $75 \%$ higher hazard of death among males ( $95 \% \mathrm{Cl}: 44 \%, 112 \%$; Table 3 ). The association slightly attenuated but persisted in the full adjusted model (hazard ratio $[\mathrm{HR}]=1.51,95 \% \mathrm{Cl}: 1.23,1.84$ ). When modelled in categories, in the unadjusted model, the hazard of death of male with the medium AL burden (score: 2-4) was 1.68 times than hazard of death of those with a lower AL burden (score: $0-1$ ); Male with a high AL burden (Score: 5-9) had a more than three-fold hazard of death than those with a lower AL burden (score: 0-1). These associations persisted after adjustment of socio-demographics and lifestyles. In the fully adjusted model, males with a medium AL burden (score: $2-4$ ) had a $34 \%$ higher hazard of death than those with a low AL burden (score: 0-1). Males with a high AL burden (score: 5-9) had a more than two-fold hazard of death than those with a low AL burden (score: $0-1$ ).

\section{Association between Allostatic Load and Mortality among Females}

Over an average follow-up period of 3.9 years, 787 deaths (51.8\%) occurred. A total of 477 females died (58.9\%); the overall death rate was 161.3 per 1,000 person-years. The death rates for females with an $\mathrm{AL}$ score of 0-1 (low burden), 2-4 (medium burden), and 5-9 (high burden) were 121.1, 174.8, and 252.6 per 1,000 person-years, respectively (Table 3).

In the unadjusted Cox model, per unit higher AL (modelled continuously) was significantly associated with a $45 \%$ higher hazard of death among females (95\% Cl: $23 \%, 72 \%$; Table 3$)$. However, the association attenuated and became insignificant after adjusting for socio-demographics (age, sex, ethnicity, education, and marital status); similar results were observed when smoking and exercise were additionally adjusted $(\mathrm{HR}=1.16,95 \% \mathrm{Cl}: 0.97,1.38)$. When modelled in categories, the HR was 1.44 (95\% Cl: $1.17,1.79)$ and $2.11(95 \% \mathrm{Cl}: 1.44,3.10)$ for females with an AL score of 2-4 and 5-9, respectively, compared with those with a score of $0-1$ in the unadjusted model. After multivariable adjustment, females with an AL score of 2-4 and 5-9 had a $14 \%$ and $37 \%$ higher hazard of death, although the associations were not significant.

\section{Discussion}


The present study aimed to explore the association between AL burden and all-cause mortality among men and women aged at least 60 years in China. We found that older men with high AL burden had a more than two-fold hazard of death than those with a low AL burden. However, the association was less clear among women. These findings were in line with previous studies showing men tend to have higher AL with higher risk of death than women, and gender difference among AL score and cause-specific mortality risk including infectious diseases, cardiometabolic disease, and malignant neoplasm $[14,26$, 27]. One possible explanation for the sex difference in the association between AL and mortality among older adults is that older women might be less vulnerable to stress men due to sex difference in hippocampal formation in humans $[10,16,21]$. In addition, it has been shown that estrogen plays an important role in brain with the development of aging, aiming to maintain allostasis when facing physiological stress, which may be possible to protect women against age-related diseases [3, 22, 28]. Moreover, Gruenewald et al. (2006) stated that gender difference in forecasting mortality risk among older people by biomarkers; compared with female, neuroendocrine and immune related biomarkers were more predictive in male.

Previous study has identified increased risk of all-cause mortality associated with increasing AL score in men [14]. However, the adjusted model with hazard ratio is lower than Hwang et al. study. We proposed three main possible reasons why our association was weaker. First, Hwang study population ( $\geq 54$ years) were younger than our study ( $\geq 60$ years), which may be as a confounder. Second, as for AL, cortisol is a common biomarker for assessing, but this biomarker was not measured in CLHLS, which causes results cannot be truly reflect association between mortality and AL. Finally, the cut-points were different in previous study and our study. Previous study used one cut-off points for male and female while our study used sex-specific cut-off points for each biomarker.

This study has some strengths. This is among the first to investigate the association between AL and mortality using a Chinese population. Moreover, our study used of CLHLS dataset that is a large nationally representative old population survey in China. Furthermore, we updated quartile risk method for biomarkers $\mathrm{BMI}$, total cholesterol, and triglyceride due to inversely association with mortality among older adults, which may more truly reflect AL score in old people. Additionally, our study added evidence to support sex difference in the association between $A L$ and the increased risk of mortality. Finally, sexspecific cut-off points were used to construct the AL score may more truly reflect association between $\mathrm{AL}$ and mortality in different gender compared previous study.

Despite these strengths, we acknowledge some limitations. First, we did not include any primary neuroendocrine biomarkers such as cortisol in constructing the AL score due to data limitation. The cortisol biomarker plays an important role in responding stress, which needs repeated measurements within 1-2 days which causes difficulties to measure in large national survey [7]. Inclusion of cortisol biomarker maybe improve our power of AL score predictions for mortality. Additionally, we classified AL biomarkers based on sex-specific quartiles; however, these measures may vary over time, leading to misclassification. Lastly, participants in this study were residents in eight longevity areas, our results may other regions of China.

Page $7 / 15$ 


\section{Conclusion}

In conclusion, our study showed that higher AL burden was associated with increased all-cause mortality among Chinese men aged at least 60 years. We did not find strong evidence among women. Intervention programs targeting modifiable components of the AL burden may help prolong lifespan for older adults, especially men, in China.

\section{Abbreviations}

AL: allostatic load; DHEA-S: dehydroepiandrosterone sulphate; BP: blood pressure; CLHLS: Chinese Longitudinal Healthy Longevity Survey; SBP: systolic BP; DBP: diastolic BP; BMI: body mass index; HDL: total cholesterol, high density lipoprotein; CRP: C-reactive protein.

\section{Declarations}

\section{Ethics approval and consent to participate:}

The study design was approved by the ethical review committee of Peking University. All participants gave written informed consent.

\section{Consent to publish:}

Not Applicable

\section{Availability of data and materials:}

The raw data is available on website: https://opendata.pku.edu.cn/dataset.xhtml? persistentld=doi:10.18170/DVN/WBO7LK

\section{Competing interests:}

Dr. Chenkai Wu provides paid consultant services to Health Keepers, a start- up health data analytics company in China. Other authors have no conflict of interests to disclose.

\section{Funding:}

The data analyzed in this paper were provided by the Chinese Longitudinal Healthy Longevity Study (CLHLS) which has been jointly supported by National Natural Sciences Foundation of China (71490732) and the National Key R\&D Program of China (2018YFC2000400); Suzhou Municipal Science and Technology Bureau (SS2019069). The funder played no role in study design, data collection, and analysis, the decision to publish, or preparation of the manuscript. 


\section{Authors' Contributions:}

THZ conceived of and conducted the data analyses, interpreted the findings, and wrote the manuscript. LJY, HSC and HYJ contributed to manuscript revision. CKW contributed to analysis and interpretation of data and drafting and revision of the manuscript.

\section{Acknowledgements:}

Not Applicable

\section{References}

1. Beckie TM. "A systematic review of allostatic load, health, and health disparities." Biological research for nursing. 2012; 14(4): 311-346.

2. Borrell LN, Dallo FJ, Nguyen N. Racial/ethnic disparities in all-cause mortality in US adults: the effect of allostatic load. Public health reports. 2010;125(6):810-6.

3. Borrás C, Gambini J, Gómez-Cabrera MC, Sastre J, Pallardó FV, Mann GE, Viña, J. 17ß-oestradiol upregulates longevity-related, antioxidant enzyme expression via the ERK1 and ERK2 [MAPK]/NFKB cascade. Aging cell. 2005;4(3):113-8.

4. China Population (Age 60+): The 2019 Revision. 2019. Retrieved from https://population.un.org/wpp/Graphs/Probabilistic/POP/60plus/156 Accessed 22 Nov 2019.

5. China population. Worldometers. 2019. Retrieved from https://www.worldometers.info/worldpopulation/china-population/ Accessed 22 Nov 2019.

6. Crimmins EM, Johnston M, Hayward M, Seeman T. Age differences in allostatic load: an index of physiological dysregulation. Experimental gerontology. 2003;38(7):731-4.

7. Dowd JB, Simanek AM, Aiello AE. Socio-economic status, cortisol and allostatic load: a review of the literature. Int J Epidemiol. 2009;38(5):1297-309.

8. Duong MT, Bingham BA, Aldana PC, Chung ST, Sumner AE. Variation in the calculation of allostatic load score: 21 examples from NHANES. Journal of racial ethnic health disparities. 2017;4(3):45561.

9. Geronimus AT, Hicken M, Keene D, Bound J. "Weathering" and age patterns of allostatic load scores among blacks and whites in the United States. American journal of public health. 2006;96(5):82633.

10. Gould E, Westlind-Danielsson A, Frankfurt M, McEwen BS. Sex differences and thyroid hormone sensitivity of hippocampal pyramidal cells. J Neurosci. 1990;10(3):996-1003.

11. Gu D, Dupre ME. Assessment of reliability of mortality and morbidity in the 1998-2002 CLHLS waves. In: Healthy Longevity in China. Dordrecht: Springer; 2008. pp. 99-116. 
12. Gruenewald TL, Seeman TE, Ryff CD, Karlamangla AS, Singer BH Combinations of biomarkers predictive of later life mortality. Proceedings of the National Academy of Sciences. 2006; 103(38): 14158-14163.

13. Gruenewald TL, Seeman TE, Karlamangla AS, Sarkisian CA. Allostatic load and frailty in older adults. J Am Geriatr Soc. 2009;57(9):1525-31.

14. Hwang AC, et al. Predicting all-cause and cause-specific mortality by static and dynamic measurements of allostatic load: a 10-year population-based cohort study in Taiwan. J Am Med Dir Assoc. 2014;15(7):490-6.

15. Juster RP, McEwen BS, Lupien SJ. Allostatic load biomarkers of chronic stress and impact on health and cognition. Neuroscience Biobehavioral Reviews. 2010;35(1):2-16.

16. Kimura D. Sex differences in the brain. Sci Am. 1992;267(3):118-25.

17. Karlamangla AS, Singer BH, Seeman TE. Reduction in allostatic load in older adults is associated with lower all-cause mortality risk: MacArthur studies of successful aging. Psychosom Med. 2006;68(3):500-7.

18. Karlamangla AS, et al. Allostatic load as a predictor of functional decline: MacArthur studies of successful aging. J Clin Epidemiol. 2002;55(7):696-710.

19. Lv YB, et al. Triglycerides paradox among the oldest old:"the lower the better?". J Am Geriatr Soc. 2019;67(4):741-8.

20. Levine ME, Crimmins EM. A comparison of methods for assessing mortality risk. American Journal of Human Biology. 2014;26(6):768-76.

21. McEwen BS. Protective and damaging effects of stress mediators. New England journal of medicine. 1998;338(3):171-9.

22. Paulson PE, Minoshima S, Morrow TJ, Casey KL. Gender differences in pain perception and patterns of cerebral activation during noxious heat stimulation in humans. Pain. 1998;76(1-2):223-9.

23. Robertson T, Beveridge G, Bromley C. Allostatic load as a predictor of all-cause and cause-specific mortality in the general population: evidence from the Scottish Health Survey. PloS one. 2017; 12(8).

24. Seeman TE, McEwen BS, Rowe JW, Singer BH Allostatic load as a marker of cumulative biological risk: MacArthur studies of successful aging. Proceedings of the National Academy of Sciences. 2001; 98(8): 4770-4775.

25. Seeman T, et al. Modeling multisystem biological risk in young adults: the Coronary Artery Risk Development in Young Adults Study. American Journal of Human Biology: The Official Journal of the Human Biology Association. 2010;22(4):463-72.

26. Seeman TE, et al. Social relationships, gender, and allostatic load across two age cohorts. Psychosom Med. 2002;64(3):395-406.

27. Thomson EM, Kalayci $\mathrm{H}$, Walker M. Cumulative toll of exposure to stressors in Canadians: An allostatic load profile. Health Rep. 2019;30(6):14-21. 
28. Vina J, et al. Why females live longer than males: control of longevity by sex hormones. Science of aging knowledge environment: SAGE KE. 2005;(23): pe17-pe17.

29. Winter JE, MacInnis RJ, Wattanapenpaiboon N, Nowson CA. BMI and all-cause mortality in older adults: a meta-analysis. Am J Clin Nutr. 2014;99(4):875-90.

30. Weverling-Rijnsburger AW, et al. Total cholesterol and risk of mortality in the oldest old. The Lancet. 1997;350(9085):1119-23.

31. Yi Z. Introduction to the chinese longitudinal healthy longevity survey (CLHLS). In: Healthy longevity in China. Dordrecht: Springer; 2008a. pp. 23-38.

32. Yi Z. Reliability of age reporting among the Chinese oldest-old in the CLHLS datasets. In: Healthy Longevity in China. Dordrecht: Springer; 2008b. pp. 61-78.

\section{Tables}

Table 1. Cut-point for each of nine biomarkers used to construct allostatic load.

\begin{tabular}{|c|c|c|}
\hline & \multicolumn{2}{|c|}{ Cut-points } \\
\hline Biomarkers & Male & Female \\
\hline $\begin{array}{l}\text { Body mass index, kg/ } \\
\mathrm{m}^{2}\end{array}$ & $\leq 19.33$ & $\leq 17.78$ \\
\hline Glucose, mmol/L & $\geq 5.13$ & $\geq 5.15$ \\
\hline Total cholesterol, mmol/L & $\leq 3.51$ & $\leq 3.71$ \\
\hline High-density lipoprotein cholesterol, mmol/L & $\leq 1.04$ & $\leq 1.06$ \\
\hline Triglyceride, $\mathrm{mmol} / \mathrm{L}$ & $\leq 0.56$ & $\leq 0.63$ \\
\hline High-sensitive $\mathrm{C}$ reactive protein, $\mathrm{mg} / \mathrm{L}$ & $\geq 2.44$ & $\geq 2.33$ \\
\hline Heart rate, beats/min & $\geq 80$ & $\geq 83$ \\
\hline Systolic blood pressure, $\mathrm{mmHg}$ & $\geq 150$ & $\geq 160$ \\
\hline Diastolic blood pressure, $\mathrm{mmHg}$ & $\geq 90$ & $\geq 90$ \\
\hline \multicolumn{3}{|c|}{$\begin{array}{l}\text { High-risk group was defined as below the sex-specific } 25 \text { th percentile for body mass index, total } \\
\text { cholesterol, high-density lipoprotein cholesterol and triglyceride. High-risk group was defined as above } \\
\text { the sex-specific } 75 \text { th percentile for glucose, high-sensitive } C \text { reactive protein, heart rate, systolic blood } \\
\text { pressure, and diastolic blood pressure. }\end{array}$} \\
\hline
\end{tabular}

Table 2. Baseline characteristics by allostatic load burden (low, medium, and high) among males and females 


\begin{tabular}{|c|c|c|c|c|c|c|c|c|}
\hline & \multicolumn{4}{|c|}{ Male $(\mathrm{N}=709)$} & \multicolumn{4}{|c|}{ Female $(\mathrm{N}=810)$} \\
\hline & $\begin{array}{l}\text { Low } \\
(n= \\
181)\end{array}$ & $\begin{array}{l}\text { Medium } \\
(n= \\
455)\end{array}$ & $\begin{array}{l}\text { High } \\
(n=73)\end{array}$ & $\begin{array}{l}\mathrm{P}- \\
\text { value }\end{array}$ & $\begin{array}{l}\text { Low } \\
(n= \\
231)\end{array}$ & $\begin{array}{l}\text { Medium } \\
(n= \\
534)\end{array}$ & $\begin{array}{l}\text { High } \\
(n=45)\end{array}$ & $\begin{array}{l}\mathrm{P} \text { - } \\
\text { value }\end{array}$ \\
\hline $\begin{array}{l}\text { Age, years, } \\
\text { mean } \pm S D\end{array}$ & $\begin{array}{l}77.6 \pm \\
10.7\end{array}$ & $\begin{array}{l}81.0 \pm \\
11.4\end{array}$ & $\begin{array}{l}84.1 \pm \\
11.0\end{array}$ & 0.042 & $\begin{array}{l}87.0 \pm \\
13.0\end{array}$ & $\begin{array}{l}91.3 \pm \\
11.1\end{array}$ & $\begin{array}{l}93.6 \pm \\
11.0\end{array}$ & 0.029 \\
\hline $\begin{array}{l}\text { Married, No. } \\
(\%)\end{array}$ & $\begin{array}{l}125 \\
(69.1 \%)\end{array}$ & $\begin{array}{l}276 \\
(60.7 \%)\end{array}$ & $\begin{array}{l}45 \\
(61.6 \%)\end{array}$ & 0.137 & $\begin{array}{l}65 \\
(28.1 \%)\end{array}$ & $\begin{array}{l}101 \\
(18.9 \%)\end{array}$ & $\begin{array}{l}7 \\
(15.6 \%)\end{array}$ & 0.010 \\
\hline $\begin{array}{l}\text { Han ethnicity, } \\
\text { No. (\%) }\end{array}$ & $\begin{array}{l}168 \\
(92.8 \%)\end{array}$ & $\begin{array}{l}402 \\
(88.4 \%)\end{array}$ & $\begin{array}{l}68 \\
(93.2 \%)\end{array}$ & 0.152 & $\begin{array}{l}210 \\
(90.9 \%)\end{array}$ & $\begin{array}{l}471 \\
(88.2 \%)\end{array}$ & $\begin{array}{l}38 \\
(84.4 \%)\end{array}$ & 0.354 \\
\hline $\begin{array}{l}\text { Any education, } \\
\text { No. (\%) }\end{array}$ & $\begin{array}{l}119 \\
(65.8 \%)\end{array}$ & $\begin{array}{l}294 \\
(64.6 \%)\end{array}$ & $\begin{array}{l}44 \\
(60.3 \%)\end{array}$ & 0.707 & $\begin{array}{l}50 \\
(21.7 \%)\end{array}$ & $\begin{array}{l}55 \\
(10.3 \%)\end{array}$ & $\begin{array}{l}3 \\
(6.7 \%)\end{array}$ & 0.000 \\
\hline Smoking, No. (\%) & & & & 0.418 & & & & 0.800 \\
\hline $\begin{array}{l}\text { Current } \\
\text { Smoker }\end{array}$ & $\begin{array}{l}71 \\
(39.2 \%)\end{array}$ & $\begin{array}{l}170 \\
(37.4 \%)\end{array}$ & $\begin{array}{l}24 \\
(32.9 \%)\end{array}$ & & $\begin{array}{l}6 \\
(2.6 \%)\end{array}$ & $\begin{array}{l}23 \\
(4.3 \%)\end{array}$ & $\begin{array}{l}1 \\
(2.2 \%)\end{array}$ & \\
\hline Past Smoker & $\begin{array}{l}22 \\
(12.2 \%)\end{array}$ & $\begin{array}{l}71 \\
(15.6 \%)\end{array}$ & $\begin{array}{l}16 \\
(21.9 \%)\end{array}$ & & $\begin{array}{l}5 \\
(2.2 \%)\end{array}$ & $\begin{array}{l}11 \\
(2.1 \%)\end{array}$ & 0 & \\
\hline Never & $\begin{array}{l}88 \\
(48.6 \%)\end{array}$ & $\begin{array}{l}214 \\
(47.0 \%)\end{array}$ & $\begin{array}{l}33 \\
(45.2 \%)\end{array}$ & & $\begin{array}{l}219 \\
(95.2 \%)\end{array}$ & $\begin{array}{l}498 \\
(93.6 \%)\end{array}$ & $\begin{array}{l}44 \\
(97.8 \%)\end{array}$ & \\
\hline $\begin{array}{l}\text { Exercise, No. } \\
(\%)\end{array}$ & $\begin{array}{l}55 \\
(30.6 \%)\end{array}$ & $\begin{array}{l}110 \\
(24.6 \%)\end{array}$ & $\begin{array}{l}18 \\
(25.0 \%)\end{array}$ & 0.300 & $\begin{array}{l}41 \\
(18.1 \%)\end{array}$ & $\begin{array}{l}103 \\
(19.5 \%)\end{array}$ & $\begin{array}{l}10 \\
(22.2 \%)\end{array}$ & 0.782 \\
\hline $\begin{array}{l}\text { Hypertension, } \\
\text { No. (\%) }\end{array}$ & 0 & $\begin{array}{l}97 \\
(21.6 \%)\end{array}$ & $\begin{array}{l}28 \\
(38.9 \%)\end{array}$ & 0.000 & 0 & $\begin{array}{l}153 \\
(29.3 \%)\end{array}$ & $\begin{array}{l}26 \\
(57.8 \%)\end{array}$ & 0.000 \\
\hline $\begin{array}{l}\text { Diabetes, No. } \\
(\%)\end{array}$ & $\begin{array}{l}3 \\
(1.6 \%)\end{array}$ & $4(0.9 \%)$ & $\begin{array}{l}6 \\
(8.3 \%)\end{array}$ & 0.001 & 0 & $\begin{array}{l}10 \\
(1.9 \%)\end{array}$ & $\begin{array}{l}2 \\
(4.4 \%)\end{array}$ & 0.013 \\
\hline $\begin{array}{l}\text { Heart disease, } \\
\text { No. }(\%)\end{array}$ & $\begin{array}{l}10 \\
(5.5 \%)\end{array}$ & $\begin{array}{l}27 \\
(6.0 \%)\end{array}$ & $\begin{array}{l}5 \\
(6.9 \%)\end{array}$ & 0.921 & $\begin{array}{l}10 \\
(4.5 \%)\end{array}$ & $\begin{array}{l}40 \\
(7.6 \%)\end{array}$ & $\begin{array}{l}12 \\
(26.7 \%)\end{array}$ & 0.000 \\
\hline Stroke, No. (\%) & $\begin{array}{l}8 \\
(4.4 \%)\end{array}$ & $\begin{array}{l}18 \\
(4.0 \%)\end{array}$ & $\begin{array}{l}7 \\
(10.0 \%)\end{array}$ & 0.105 & $\begin{array}{l}14 \\
(6.2 \%)\end{array}$ & $\begin{array}{l}29 \\
(5.5 \%)\end{array}$ & $\begin{array}{l}2 \\
(4.4 \%)\end{array}$ & 0.878 \\
\hline $\begin{array}{l}\text { Pulmonary, } \\
\text { No. (\%) }\end{array}$ & $\begin{array}{l}18 \\
(10.0 \%)\end{array}$ & $\begin{array}{l}45 \\
(9.9 \%)\end{array}$ & $\begin{array}{l}11 \\
(15.3 \%)\end{array}$ & 0.374 & $\begin{array}{l}10 \\
(4.4 \%)\end{array}$ & $\begin{array}{l}38 \\
(7.2 \%)\end{array}$ & $\begin{array}{l}1 \\
(2.2 \%)\end{array}$ & 0.181 \\
\hline $\begin{array}{l}\text { Arthritis, No. } \\
(\%)\end{array}$ & $\begin{array}{l}18 \\
(10.0 \%)\end{array}$ & $\begin{array}{l}64 \\
(14.2 \%)\end{array}$ & $\begin{array}{l}14 \\
(19.2 \%)\end{array}$ & 0.132 & $\begin{array}{l}44 \\
(19.2 \%)\end{array}$ & $\begin{array}{l}79 \\
(15.0 \%)\end{array}$ & $\begin{array}{l}5 \\
(11.1 \%)\end{array}$ & 0.224 \\
\hline Cancer, No. (\%) & $\begin{array}{l}1 \\
(0.6 \%)\end{array}$ & $1(0.2 \%)$ & 0 & 0.591 & 0 & $5(1.0 \%)$ & $\begin{array}{l}1 \\
(2.2 \%)\end{array}$ & 0.133 \\
\hline
\end{tabular}


Table 3. Association between allostatic load and mortality among males and females.

\begin{tabular}{|c|c|c|c|c|}
\hline & \multicolumn{4}{|l|}{ Males $(\mathrm{N}=709)$} \\
\hline & \multirow[t]{2}{*}{$\begin{array}{l}\text { Events per } 1,000 \text { PYs } \\
(95 \% \mathrm{Cl})\end{array}$} & Unadjusted & $\begin{array}{l}\text { Demographically } \\
\text { adjusted a }\end{array}$ & $\begin{array}{l}\text { Fully } \\
\text { adjusted } b\end{array}$ \\
\hline & & \multicolumn{3}{|c|}{ Hazard ratio $(95 \% \mathrm{Cl})$} \\
\hline $\begin{array}{l}\text { AL } \\
\text { (continuously) }\end{array}$ & & $\begin{array}{l}1.75(1.44 \\
2.12)\end{array}$ & $1.51(1.24,1.84)$ & $\begin{array}{l}1.51(1.23 \\
1.84)\end{array}$ \\
\hline \multicolumn{5}{|l|}{ AL category } \\
\hline Low $(0-1)$ & $66.1(50.7,86.1)$ & Ref. & Ref. & Ref. \\
\hline Medium (2-4) & $110.4(96.3,126.7)$ & $\begin{array}{l}1.68(1.24 \\
2.26)\end{array}$ & $1.36(1.00,1.83)$ & $\begin{array}{l}1.34(0.99 \\
1.81)\end{array}$ \\
\hline \multirow[t]{3}{*}{ High (5-9) } & $201.3(153.0,265.0)$ & $\begin{array}{l}3.06(2.09, \\
4.48)\end{array}$ & $2.29(1.56,3.37)$ & $\begin{array}{l}2.28(1.55 \\
3.36)\end{array}$ \\
\hline & \multicolumn{4}{|l|}{ Females $(\mathrm{N}=810)$} \\
\hline & \multirow[t]{2}{*}{$\begin{array}{l}\text { Events per } 1,000 \text { PYs } \\
(95 \% \mathrm{Cl})\end{array}$} & Unadjusted & $\begin{array}{l}\text { Demographically } \\
\text { adjusted a }\end{array}$ & $\begin{array}{l}\text { Fully } \\
\text { adjusted }{ }^{c}\end{array}$ \\
\hline & & \multicolumn{3}{|c|}{ Hazard ratio $(95 \% \mathrm{Cl})$} \\
\hline $\begin{array}{l}\text { AL } \\
\text { (continuously) }\end{array}$ & & $\begin{array}{l}1.45(1.23, \\
1.72)\end{array}$ & $1.16(0.97,1.37)$ & $\begin{array}{l}1.16(0.97 \\
1.38)\end{array}$ \\
\hline \multicolumn{5}{|l|}{ AL category } \\
\hline $\operatorname{Low}(0-1)$ & $121.1(100.7,145.6)$ & Ref. & Ref. & Ref. \\
\hline Medium (2-4) & $174.8(156.9,194.7)$ & $\begin{array}{l}1.44(1.17, \\
1.79)\end{array}$ & $1.14(0.92,1.42)$ & $\begin{array}{l}1.14(0.92 \\
1.42)\end{array}$ \\
\hline High (5-9) & $252.6(180.5,353.5)$ & $\begin{array}{l}2.11(1.44, \\
3.10)\end{array}$ & $1.36(0.93,2.01)$ & $\begin{array}{l}1.37(0.93 \\
2.02)\end{array}$ \\
\hline \multicolumn{5}{|c|}{ Abbreviations: PY, person-year; Cl, confidence interval; AL, allostatic load. } \\
\hline \multicolumn{5}{|c|}{$\begin{array}{l}\text { Demographically adjusted model included age, ethnicity (Han vs. minority), education (any vs. none) } \\
\text { and marital status (married vs. others). }\end{array}$} \\
\hline \multicolumn{5}{|c|}{$\begin{array}{l}\text { bFully adjusted model included age, ethnicity (Han vs. minority), education (any vs. none), and marital } \\
\text { status (married vs. others), smoking (current vs. previous or never), exercise (yes vs. no) }\end{array}$} \\
\hline
\end{tabular}




\section{Figures}

\section{The distribution of allostatic load score among male}

$(\mathrm{N}=709)$

\section{0}

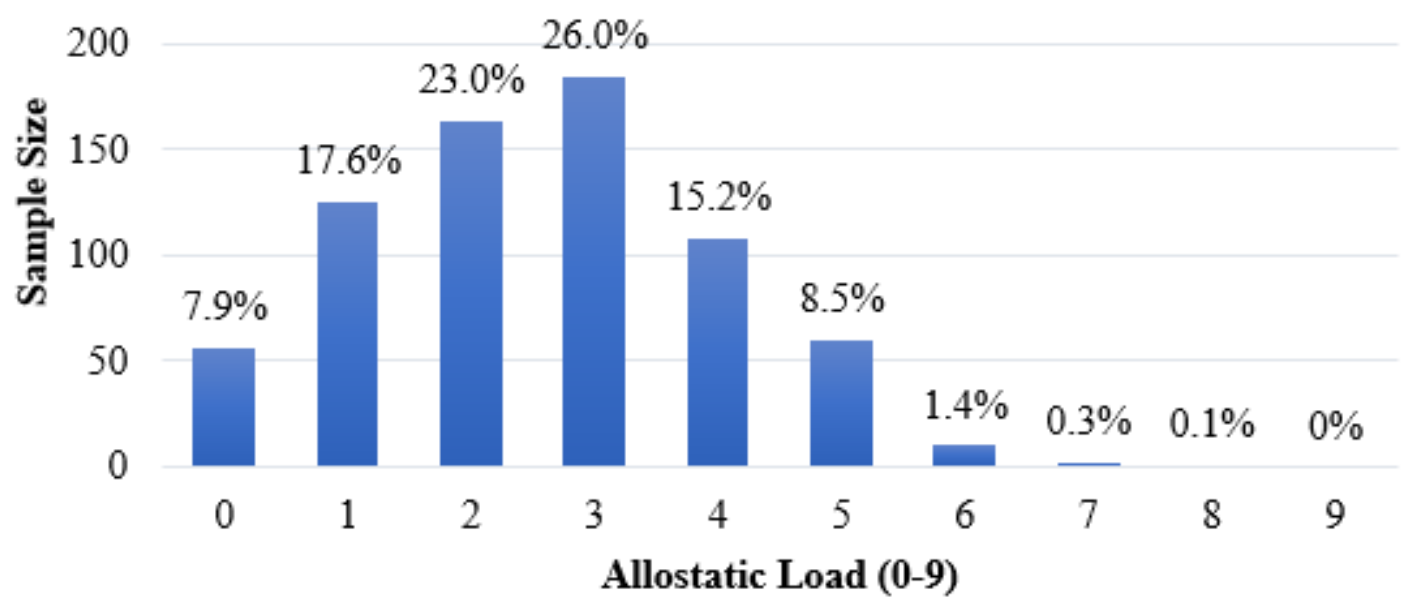

The distribution of allostatic load score among female $(\mathbf{N}=\mathbf{8 1 0})$

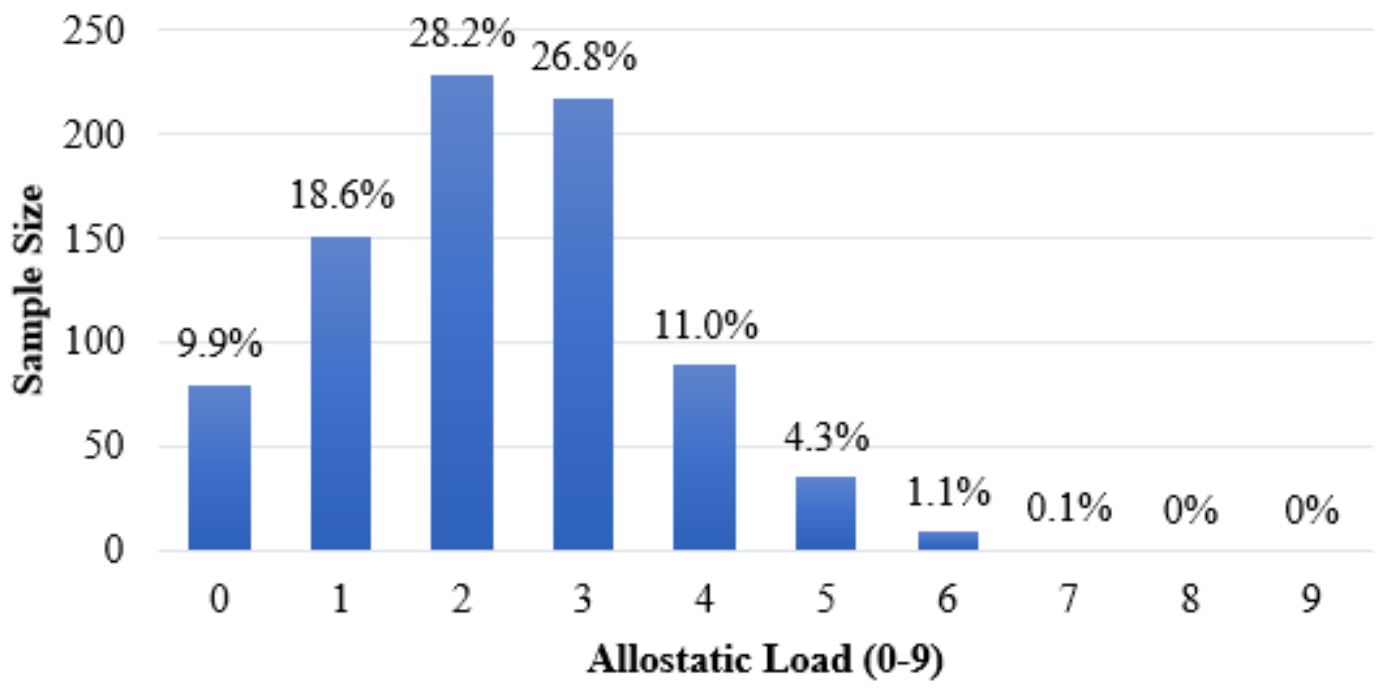

\section{Figure 1}

Distribution of sample size by allostatic load score among males and females. The above figure is the distribution of allostatic load score among male. The below figure is the distribution of allostatic load score among female. The distribution of the AL score (range: 0-9) is right-skewed for both males and females; only $13(1.8 \%)$ males and $10(1.2 \%)$ females had a score of $6-9$, respectively 


\section{Supplementary Files}

This is a list of supplementary files associated with this preprint. Click to download.

- TableS1.docx 